\title{
The Effects of Peer-Based Instant Response System to Promote Learning Performance, Intrinsic Motivation and Self-Efficacy
}

\author{
Wen-Jye Shyr *, Ying-Ming Hsieh and Ching-Huei Chen
}

check for updates

Citation: Shyr, W.-J.; Hsieh, Y.-M.; Chen, C.-H. The Effects of Peer-Based Instant Response System to Promote Learning Performance, Intrinsic Motivation and Self-Efficacy. Sustainability 2021, 13, 4320. https:// doi.org/10.3390/su13084320

Academic Editor: Hong-Ren Chen

Received: 9 March 2021

Accepted: 5 April 2021

Published: 13 April 2021

Publisher's Note: MDPI stays neutral with regard to jurisdictional claims in published maps and institutional affiliations.

Copyright: (c) 2021 by the authors. Licensee MDPI, Basel, Switzerland. This article is an open access article distributed under the terms and conditions of the Creative Commons Attribution (CC BY) license (https:// creativecommons.org/licenses/by/ $4.0 /)$.
Department of Industrial Education and Technology, National Changhua University of Education, No. 1, Jin-De Road, Changhua 500, Taiwan; shang2.wen@gmail.com (Y.-M.H.); chhchen@cc.ncue.edu.tw (C.-H.C.)

* Correspondence: shyrwj@cc.ncue.edu.tw

\begin{abstract}
This study investigated the effects of using different online instant response systems (IRSs) on students, particularly in remedial mathematics classrooms. To achieve the goals, this study applied a mixed-methods approach to examine the effects on learning performance, intrinsic motivation, and self-efficacy. The participants were the seventh-grade junior high school students; they were randomly divided into three experimental groups, Kahoot-based IRS, Quizlet-based IRS, and control group. The results indicated that students in the Kahoot-based IRS performed significantly better in mathematics learning performance and reported higher learning interests, choice, and group selfefficacy. Meanwhile, students in the Quizlet-based IRS remedial classroom reported more positively on learning interest, value, effort, and choice than to the control group.
\end{abstract}

Keywords: instant response systems; learning performance; intrinsic motivation; self-efficacy

\section{Introduction}

With digital technology advances, the teaching forms have changed dramatically over the past decades. Teachers are encouraged to adopt and integrate technology tools that enhance teaching effectiveness and efficiency. While significant attention has been paid to formal learning classrooms regarding how technology tools are utilized and implemented, little is known about informal learning settings, such as remedial instruction. The purpose of remedial instruction is to provide assistance to students who have temporarily in needs of special attention in their studies. In attempting to enhance remedial instruction, many teachers still use traditional teaching methods, for example, teacher-centered slide presentations. This way of teaching enriches the learning content but reduces the students active learning and interaction. Students take a passive role in acquiring knowledge, and their motivation for learning gradually declines.

Investigations of instant response systems (IRSs) in remedial instruction are extremely rare. IRSs have been shown to improve learning in various disciplines, such as science [1], health [2], management [3], mathematics [4], and engineering [5]. IRSs have documented various benefits, such as increased students' attendance and class preparation [6], attentiveness and enthusiasm [7], and in-class participation [8]. To illustrate, research on IRSs has shown pedagogical values for active learning and engagement, yet numerous studies have evaluated its effectiveness in the tertiary context [9]. An instant response system (IRS) allows instructors or teachers to get instant feedback from students while responding to specific questions stated on a screen. After clicking their answers, the results are instantly displayed; it allows individual responses by students to be collected, scored, and tabulated in a visual format for teachers but anonymously for students. The teacher can associate IRSs devices with each of individual students for specific such as testing purposes.

To shed lights on the superior effects of IRSs, this study attempts to implement IRSs to overcome the challenges faced in the traditional teacher-centered instruction. Furthermore, this study assesses learning delayed effects after exposing to different types of IRSs as well as evaluate students' motivational change and self-efficacy. 


\section{Literature Review}

\subsection{Instructional Design for Remedial Learning}

The quality of foundational remedial instruction is an important issue. To provide high-quality instruction, teachers must be equipped with teaching expertise and instructional tools to deliver instruction effectively. Using a nine-step process called the Events of Instruction created by Gagné et al. [10] is familiar; it is a systematic instructional design process that helps trainers, educators, and instructional designers structure their training sessions. Gagné's nine events also echo Bloom's Revised Taxonomy when designing an engaging and meaningful instruction. In addition, Reigeluth [11] stated that instructional design offers principles for defining the end goal of instruction, creating some intervention to assist in the transition, and carrying out effective instruction. It can help teachers integrate their subject matter knowledge and specific skills into valuable and usable teaching materials. Instructional design provides a set of foundational principles from organizational psychology, instructional psychology to educational psychology for new teachers so that they can use them appropriately and effectively without years of training [12,13].

Constructivism is a theory of knowledge that has roots in epistemology; hence, it is recognized that learners construct their knowledge and judgment from their prior experiences [14]. The study applied a mixed-methods approach to examine the effects of IRSs on seventh-grade students' intrinsic motivation, self-efficacy, and learning performance.

\subsection{Remedial Mathematics Instruction and Instant Responses Systems}

A report [15] showed that mathematics is rated as the toughest subject in the school curriculum. However, mathematics involves functional knowledge that helps individuals make informed decisions as citizens and workers [16]. Yet many students face learning difficulties in the subject of mathematics that result in low performance and a negative attitude toward mathematics [17]. Consequently, negativity toward mathematics learning has prevented students from performing mathematical computations, and further hindered learning engagement and competence [18]. Researchers have long studied methods and strategies to improve mathematics learning, attitudes, motivation, and beliefs. The implementation of technology tools has brought positive influences, as such tools produce positive results in learning and understanding mathematics concepts [19]. Researchers and practitioners have been designing and developing effective technological tools to motivate students in the learning process. For example, game-based learning (GBL) has evidenced to effectively elevate mathematics learning [20-22].

IRSs, also called Clickers, Student Response Systems (SRSs), and Audience Response Systems (ARSs), have become a necessary and important part of the classroom. IRSs work as bring your own device (BYOD) signal transmitters through which a teacher can pose questions and then collect students' responses in the classroom, with the results instantly shown to the whole class. Numerous studies have implemented IRSs to bolster student performance. For example, Caldwell [23] surveyed large university classes on the potentials of IRSs to improve classroom learning. It was found that IRSs affected student exams and created a more positive atmosphere in classrooms. Wang [24] investigated how the students' perception changed to IRSs in the school and found that game-based IRSs not only increased student engagement but maintained motivation for learning over an extended period of time. Furthermore, several meta-analysis studies support that IRSs generally provide immediate feedback, increase participation in class, and improve retention of the learned materials [25].

The effectiveness of IRSs in fostering students' learning and creating active learning experiences has been well documented in lecture-based instruction or large classrooms. IRSs are less commonly implemented in remedial classrooms. Students who attend remedial classrooms often face serious attitude barriers that hinder them from learning generic instruction [26]. Moreover, remedial students may encounter problems when connecting and applying the knowledge to future academic and vocational courses [27]. 


\subsection{Peer Interaction and IRSs for Mathematics Learning}

Peer interaction is essential for language, cognitive, and social development throughout learning. According to Webb [28], peer interaction is a group of students learn or solve problem collaboratively. In peer interaction, students who are more advanced in higher-level thinking or argumentation can help the groups to reach levels that individuals could not have reached alone $[29,30]$. Some empirical evidence supports the benefits of peer interaction for mathematics learning. For example, Webb found that mathematics learning was enhanced when peers gave explanations and asked each other questions. Such a process also enables students to clarify concepts and reorganize thinking [31,32].

Essentially, explaining and negotiating meanings, sharing knowledge/experiences, constructing arguments, and developing justifications are important processes that should be encouraged in peer interaction. To incorporate peer interaction-based instruction in the remedial mathematics class is a challenge. One suggested solution is to adopt any new and emerging educational technologies that allow peer interaction. Using IRSs, students can express their judgments by pressing a button on a handheld remote control electronic device to indicate their answers to a multiple-choice question projected on a screen [33-35]. In this study, we seek to examine how peers use different IRSs to support their learning outcomes.

\section{Purposes of the Study}

The literature reviewed above indicates that IRSs are potential avenues to design effective remedial mathematics classrooms. Peer interaction can promote students' learning and development, the present study incorporated and examined different IRSs (Kahoot and Quizlet Live) to engage students in the remedial mathematics classrooms and to promote intrinsic motivation and self-efficacy. Furthermore, an investigation was undertaken to examine the effectiveness of IRS-integrated remedial classrooms, addressing the following questions:

(1) How did the different IRS-integrated remedial classroom interventions influence the students' mathematics learning performance?

(2) How did the different IRS-integrated remedial classroom interventions affect the students' intrinsic motivation?

(3) How did the different IRS-integrated remedial classroom interventions influence the students' group learning self-efficacy?

\section{Methodology}

\subsection{Design and Participants}

This study adopts mixed-method research, containing quantitative and qualitative data, to gauge the effects of different IRS types on students' learning performance, intrinsic motivation, and self-efficacy for group learning. The qualitative data includes student interviews regarding their perceptions of their overall learning experience.

A total of 36 (17 male and 19 female) seventh grade students were recruited and participated in this study. The students participated because they had enrolled in remedial courses after school hours. The remedial courses are for those who are academically underachieving and who require additional instruction for remediation. These participants were randomly assigned to three treatment groups based on their intact classes: (1) Kahootbased IRS (12 students: six male and six female), (2) Quizlet-based IRS (12 students: five male and seven female), and (3) a conventional control group (12 students: nine male and three female). In each group, students were then assigned to three-member teams; thus, there were four teams in each group. The same instructor taught all three classes.

\subsection{Learning Contents}

The learning contents for this study concerned mathematics functions and graphics. The learning goals included (1) to understand that a function is a correspondence and can be found from a function relationship, (2) to understand how the quantitative relationships, such as proportional and functional relationships, can be applied in real life, and (3) to 
apply the function to solve the problem and to formulate an arithmetic formula. These learning goals were aligned with the seventh grade curriculum standards.

\subsection{Kahoot-Based IRS and Quizlet-Based IRS}

Kahoot is a free online game-based IRS that can be freely assessed and operated by any device with a web browser or a downloaded app. Kahoot allows teachers to create a series of multiple-choice questions with real-time histogram results of student responses. Kahoot can be played in solitary or collaborative modes. In collaborative modes, students in teams work together to solve problems that appear on a shared screen. Many teachers use Kahoot to create online questions or homework to enhance classroom interaction and promote student social learning and collaboration. Figure 1 illustrates the classroom collaboration activities with Kahoot.

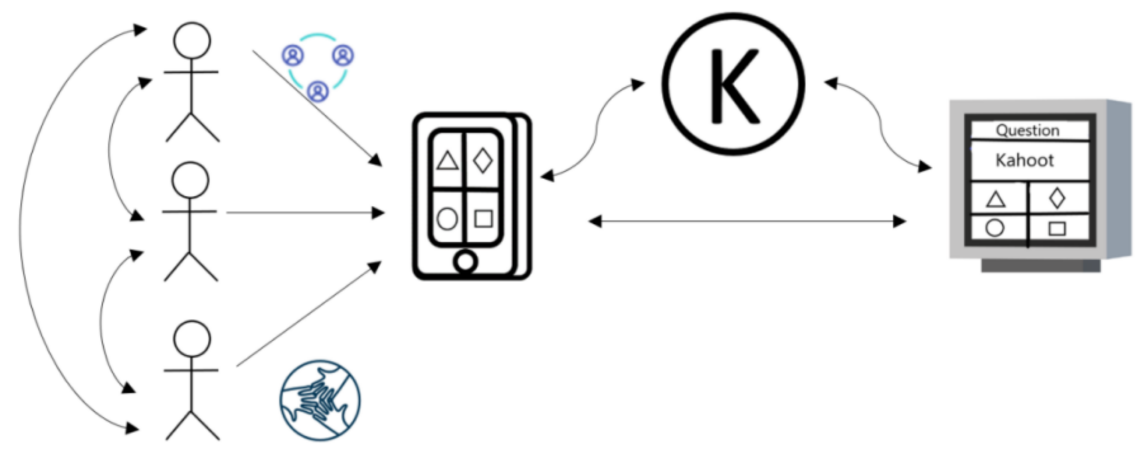

Figure 1. The students in the team collaborate to solve problems by mobile devices and the shared screen.

Quizlet [36] is a globally recognized online IRS with over 100 million user-centered study sets and 40 million users every month. In spring 2016, the Quizlet design team added a new and novelty game called Quizlet Live, a team-based game that randomly groups students into sections to compete with other teams. As shown in Figure 2, the monitoring program uses a histogram to summarize the teams' answers and publicly displays the whole's response. Kahoot and Quizlet Live are both web-enhanced IRSs that encourage classroom interaction, yet they have some differences in terms of appearance, functionality, feedback, and choices. Table 1 compares the differences between Kahoot and Quizlet Live.

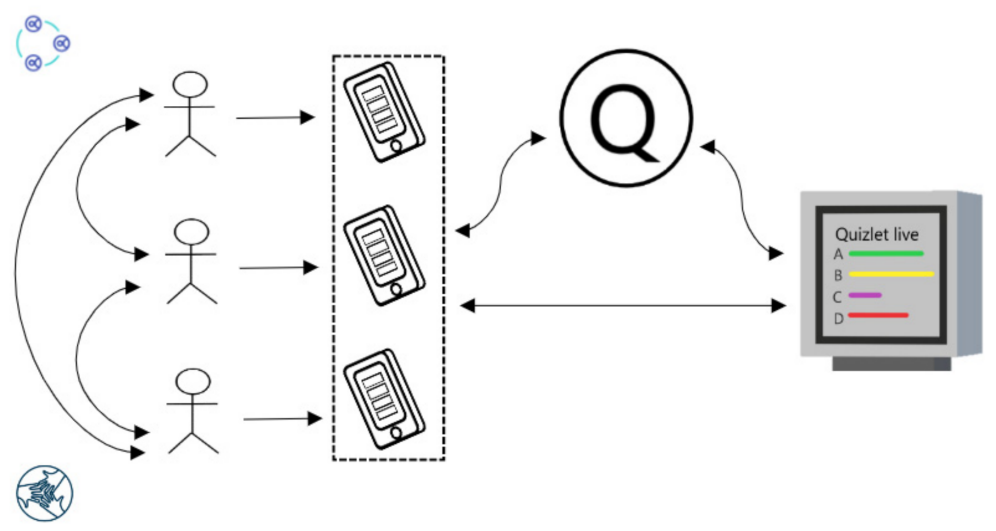

Figure 2. Students in teams work collaboratively to solve problems, and the students use their mobile devices to connect to the shared screen.

\subsection{Instrument}

This study's research tools included pre-, post-, and delayed mathematics learning performance tests and questionnaires that measured students' intrinsic motivation and self-efficacy. 
Table 1. Kahoot-based and Quizlet-based IRS comparison.

\begin{tabular}{lll}
\hline \multicolumn{1}{c}{ Kahoot-Based IRS } & \multicolumn{1}{c}{ Quizlet-Based IRS } \\
\hline \multirow{2}{*}{ Appearance } & $\begin{array}{l}\text { The question is displayed on the } \\
\text { projection screen for all groups, and } \\
\text { the answers for the question are } \\
\text { shown on the users' personal devices. } \\
\text { There is a limit on the number of } \\
\text { words for each question. }\end{array}$ & $\begin{array}{l}\text { Questions and answers are displayed } \\
\text { on the user's devices. There is no } \\
\text { limit on the number of words for } \\
\text { each question. }\end{array}$ \\
\hline \multirow{3}{*}{ Functionality } & $\begin{array}{l}\text { After all the users have answered the } \\
\text { same question or the time expires, } \\
\text { they will enter the next question. }\end{array}$ & $\begin{array}{l}\text { All of the users can enter the next } \\
\text { question after answering the question } \\
\text { or after the response time expires. }\end{array}$ \\
\hline & $\begin{array}{l}\text { Users receive just-in-time feedback } \\
\text { and see how all the groups are doing. } \\
\text { The feedback shows only the correct } \\
\text { answer to the question. }\end{array}$ & $\begin{array}{l}\text { Users receive just-in-time feedback } \\
\text { and see how all the groups are doing. } \\
\text { The feedback only shows the correct } \\
\text { answer to each question. }\end{array}$ \\
\hline \multirow{2}{*}{ Choices } & $\begin{array}{l}\text { The questions are shown in } \\
\text { multiple-choice or true/false formats. } \\
\text { The answers to the questions } \\
\text { are static. }\end{array}$ & $\begin{array}{l}\text { The answers to the questions are } \\
\text { dynamic. The question types include } \\
\text { multiple-choice, true/false, and } \\
\text { fill-in-the-blank. }\end{array}$ \\
\hline
\end{tabular}

\subsubsection{Pre-/Post-/Delayed Mathematics Learning Performance Tests}

The pre-/post-/delayed mathematics tests were identical and consisted of 10 questions each. The questions included basic concepts of functions in mathematics, as well as advanced problem-solving questions. The course instructor created the tests based on the learning objectives defined by this study, and two experienced mathematics teachers validated the tests to ensure the questions aligned with the learning objectives. Appendix A includes basic and advanced question samples. The Cronbach's alpha reliability coefficients for the pre-/post-/delayed mathematics tests were $0.82,0.84$, and 0.81 , respectively.

\subsubsection{Intrinsic Motivation}

A Chinese version of an intrinsic motivation questionnaire was translated from Deci and Ryan [37]. The questionnaire included 25 items across six constructs-interest (four items), competence (three items), pressure (three items), value (four items), effort (four items), and choice (seven items). Table 2 shows sample items for each scale. Participants ranked seven questions on a Likert 5-point scale, with a score ranging from 1 (strongly disagree) to 5 (strongly agree). We measured the internal reliability with Cronbach's alpha for each of the subscales of intrinsic motivation, and the results were $0.91,0.87,0.86,0.92$, 0.85 , and 0.88 , respectively.

\subsubsection{Self-Efficacy of Group Learning}

The group learning self-efficacy measurement was originally adopted from Wang and Lin [38], which had originated with Pintrich et al. [39]. The measurement includes eight questions rated with a five-point Likert scale from 1 as strongly disagree to 5 as strongly agree. Table 2 displays sample items. The Cronbach's alpha reliability coefficient for the group learning self-efficacy was 0.86 .

\subsubsection{Focus Group Interviews}

We asked the participants using semi-structured, open-ended questions during the focus group interviews. These questions intended to gain deeper information about the participants' perspectives on learning experiences, with or without the facilitation of tools, regarding learning attitude, peer interaction, and learning outcomes. The following questions were included in the interviews:

(1) How does this learning experience in the remedial classroom differ from what you used to experience? 
(2) Have you observed any changes in you or in peer learning as the result of this learning experience? Can you give an example? How did the changes happen and why?

Table 2. Sample items for intrinsic motivation and group self-efficacy questionnaire.

\begin{tabular}{cl}
\hline \multicolumn{1}{c}{ Interest } & $\begin{array}{l}\text { 1. I enjoyed doing this activity very much. } \\
\text { 2. This activity was fun to do. }\end{array}$ \\
\hline \multirow{2}{*}{ Competence } & $\begin{array}{l}\text { 1. I think I am pretty good at this activity. } \\
\text { 2. I think I did pretty well at this activity, compared to other students. }\end{array}$ \\
\hline Pressure & $\begin{array}{l}\text { 1. I was anxious while working on this task. } \\
\text { 2. I felt pressured while doing these. }\end{array}$ \\
\hline \multirow{2}{*}{ Value } & $\begin{array}{l}\text { 1. I believe doing this activity could help me do better in school. } \\
\text { 2. I think this is an important activity. }\end{array}$ \\
\hline \multirow{2}{*}{ Effort } & $\begin{array}{l}\text { 1. I put a lot of effort into this. } \\
\text { 2. I tried very hard on this activity. }\end{array}$ \\
\hline \multirow{2}{*}{ 1. I believe I had some choice about doing this activity. } \\
2. I did this activity because I wanted to. \\
1. I believe that, via teamwork, we can learn the skill or knowledge from \\
the learning task. \\
2. I believe that our group can achieve a superior outcome for this \\
learning task.
\end{tabular}

\subsection{Procedure}

Participants were recruited from the crane school located in the middle of Taiwan. They were informed about the purpose of this study and provided detailed information on the research procedure in Figure 3, data collection, observations, and interviews. We assigned participants in their intact classrooms and divided them into two experimental groups and one control group. The length study duration was two hours a week over a three-week period.

Firstly, at the beginning of the study, we asked all students to complete a pre-test of mathematics performance. Secondly, students were engaged in some activities for four weeks. For the first three weeks, the teacher introduced the activities and gave examples to attract all students' attention. Every group was assigned to do different activities. For two experiment groups, they played Kahoot and Quiziet live; as for the control group, they discussed with peers and completed the learning sheet. After that, the teacher introduced the linear function course and gave examples to attract all students' attention. Students of different groups also did the activities mentioned above. Then, they discussed with peers and answered questions on the learning sheet. In the end, all students were required to give a presentation and survey. During the second week, students were asked to conduct the posttest on mathematics performance and have an interview. The last week, students were required to have a delayed test.

After completing the instruction activities, immediately conducted focus group interviews in separate sessions. Focus group interviews are designed to reveal the participants' views on the learning experience in the remedial classroom and their perceptions of group activities and discussions. The focus group interviews were audiotaped and later transcribed. 


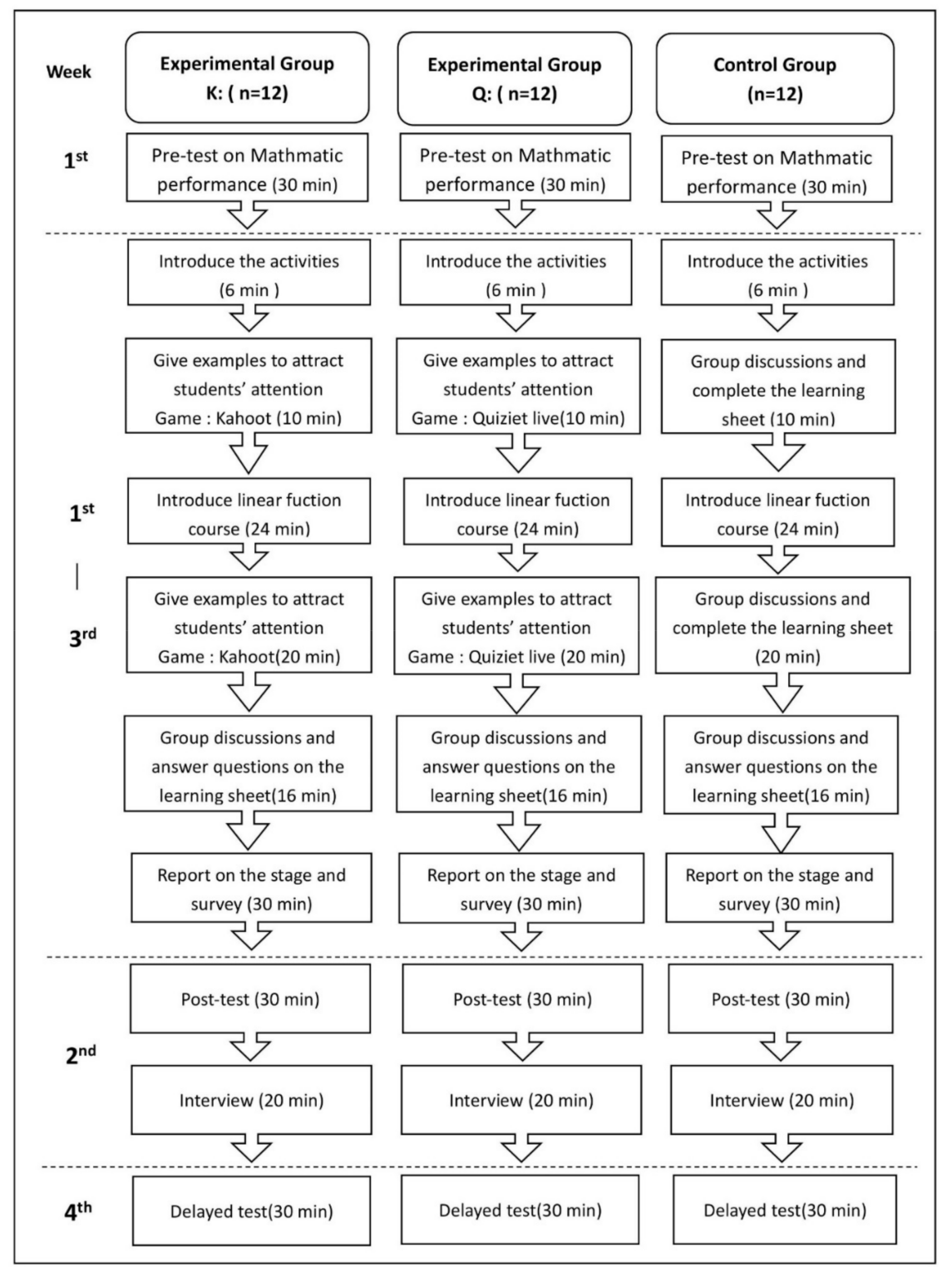

Figure 3. Research procedure.

\section{Results}

\subsection{Mathematics Learning Performance}

We employed ANCOVA to make a comparison among three groups in the mathematics learning performance. Table 3 reported the mean values and standard deviations (S.D.) of the mathematics learning performance. The results illustrated no statistical difference among the three groups in the pre-test: $\mathrm{F}(2,36)=0.89, p>0.05$, partial $\eta^{2}=0.20$. But the ANCOVA results illustrated a significant difference in the post-test: $\mathrm{F}(2,36)=11.84$, $p<0.001$, partial $\eta^{2}=0.42$. Similarly, in the delayed test: $\mathrm{F}(2,36)=17.69, p<0.001$, partial $\eta^{2}=0.52$. The comparison LSD analysis indicated that the mean values for the Kahootbased IRS group in the post-test $(\mathrm{M}=88.33, \mathrm{SD}=14.67)$ were statistically higher than for the Quizlet-based IRS $(\mathrm{M}=71.67, \mathrm{SD}=15.28)$ and traditional groups $(\mathrm{M}=59.17, \mathrm{SD}=17.82)$. Furthermore, the Kahoot-based IRS group $(M=90.83, S D=9.00)$ obtained significantly higher delayed test scores than the Quizlet-based IRS (M =65.00, $\mathrm{SD}=16.78)$ and traditional groups $(M=58.33, S D=18.99)$. This finding implies that the Kahoot-based IRS with peer learning improved the students' mathematics learning performance in comparison with the Quizlet-based IRS and traditional learning. 
Table 3. Descriptive statistics and results of one-way ANCOVA on students' mathematics pre-, post-, and delayed learning performance tests.

\begin{tabular}{|c|c|c|c|c|c|c|c|c|}
\hline Variable & Group & $\mathbf{N}$ & Mean & SD & SE & $F$ & $\eta^{2}$ & Observed Power \\
\hline \multirow{3}{*}{ Pre-test } & Kahoot & 12 & 37.50 & 16.58 & 4.87 & 0.89 & 0.20 & 0.79 \\
\hline & Quizlet & 12 & 35.00 & 14.46 & 4.17 & & & \\
\hline & Traditional & 12 & 36.67 & 13.02 & 3.76 & & & \\
\hline \multirow{3}{*}{ Post-test } & Kahoot & 12 & 88.33 & 14.67 & 4.23 & $11.84^{* * *}$ & 0.42 & 0.99 \\
\hline & Quizlet & 12 & 71.67 & 15.28 & 4.41 & & & \\
\hline & Traditional & 12 & 59.17 & 17.82 & 5.14 & & & \\
\hline \multirow{3}{*}{ Delayed test } & Kahoot & 12 & 90.83 & 9.00 & 2.59 & $17.69^{* * *}$ & 0.52 & 1.00 \\
\hline & Quizlet & 12 & 65.00 & 16.78 & 4.84 & & & \\
\hline & Traditional & 12 & 58.33 & 18.99 & 5.48 & & & \\
\hline
\end{tabular}

\subsection{Intrinsic Motivation}

MANOVA was conducted to determine the differences of IRSs in the six subscales of intrinsic motivation. The Leven's test of homogeneity of variance was achieved. Table 4 indicated a significant difference among groups in intrinsic motivation (Wilk's Lambda $=0.34$, $p<0.001)$. The subsequent ANOVA showed that interest $(\mathrm{F}=8.98, p<0.001)$, value $(\mathrm{F}=4.23$, $p<0.05)$, effort $(\mathrm{F}=7.65, p<0.01)$, and choice $(\mathrm{F}=5.10, p<0.05)$ resulted in significant multivariate effects, while competence and pressure did not. Post-hoc comparisons (Tukey HSD) disclosed that the Kahoot-based IRS ( $\mathrm{M}=4.41, \mathrm{SD}=0.52)$ and Quizlet-based IRS $(\mathrm{M}=4.52, \mathrm{SD}=0.65)$ groups reported significantly higher interest than the control group $(\mathrm{M}=3.58, \mathrm{SD}=0.59)$. In relation to value and effort, the significant differences resided between Quizlet-based IRS and the control group. From the descriptive statistics, students in the Quizlet-based IRS group reported higher mean scores in value $(\mathrm{M}=4.33, \mathrm{SD}=0.75)$ and effort $(\mathrm{M}=4.12, \mathrm{SD}=0.68)$ than the students in the control group. Finally, choice was significant, as the Kahoot-based IRS ( $\mathrm{M}=3.97, \mathrm{SD}=0.34$ ) and Quizlet-based IRS ( $\mathrm{M}=3.73$, $\mathrm{SD}=0.24)$ groups reported significantly higher perception of choice than the control group $(\mathrm{M}=3.55, \mathrm{SD}=0.36)$.

Table 4. Descriptive statistics and MANOVA results for six subscales of intrinsic motivation.

\begin{tabular}{|c|c|c|c|c|c|c|c|c|c|}
\hline Subscale & Group & Mean & SD & Value & $\mathbf{F}$ & df & Error df & PES & Post hoc (Tukey HSD) \\
\hline \multirow{3}{*}{ Interest } & Kahoot & 4.41 & 0.52 & & $8.98^{* * *}$ & 2 & & 0.35 & \multirow{3}{*}{$\mathrm{K}>\mathrm{T}, \mathrm{Q}>\mathrm{T}$} \\
\hline & Quizlet & 4.52 & 0.65 & & & & & & \\
\hline & Traditional & 3.58 & 0.59 & & & & & & \\
\hline \multirow{3}{*}{ Competence } & Kahoot & 4.11 & 0.76 & & 2.42 & 2 & & 0.13 & \\
\hline & Quizlet & 4.02 & 0.89 & & & & & & \\
\hline & Traditional & 3.44 & 0.75 & & & & & & \\
\hline \multirow{3}{*}{ Pressure } & Kahoot & 2.52 & 1.11 & & 0.71 & 2 & & 0.04 & \\
\hline & Quizlet & 2.11 & 0.93 & & & & & & \\
\hline & Traditional & 2.11 & 0.90 & & & & & & \\
\hline \multirow{3}{*}{ Value } & Kahoot & 4.27 & 0.69 & & $4.23 *$ & 2 & & 0.20 & \multirow{3}{*}{$\mathrm{Q}>\mathrm{T}$} \\
\hline & Quizlet & 4.33 & 0.75 & & & & & & \\
\hline & Traditional & 3.60 & 0.57 & & & & & & \\
\hline
\end{tabular}


Table 4. Cont.

\begin{tabular}{|c|c|c|c|c|c|c|c|c|c|}
\hline Subscale & Group & Mean & SD & Value & $\mathbf{F}$ & df & Error df & PES & Post hoc (Tukey HSD) \\
\hline \multirow{3}{*}{ Effort } & Kahoot & 3.66 & 0.55 & & $7.65^{* *}$ & 2 & & 0.31 & \multirow{3}{*}{$\mathrm{Q}>\mathrm{T}$} \\
\hline & Quizlet & 4.12 & 0.68 & & & & & & \\
\hline & Traditional & 3.16 & 0.70 & & & & & & \\
\hline \multirow{3}{*}{ Choice } & Kahoot & 3.97 & 0.34 & & $5.10 *$ & 2 & & 0.23 & \multirow{3}{*}{$\mathrm{K}>\mathrm{T}, \mathrm{Q}>\mathrm{T}$} \\
\hline & Quizlet & 3.73 & 0.24 & & & & & & \\
\hline & Traditional & 3.55 & 0.36 & & & & & & \\
\hline Wilk's lambda & & & & 0.34 & $3.36^{* * *}$ & 12 & 56 & 0.42 & \\
\hline
\end{tabular}

\subsection{Self-Efficacy of Group Learning}

One-way analysis of variance (ANOVA) was performed to examine the effects of different treatments on the self-efficacy of group learning. The results showed that there was a significant difference between groups: $\mathrm{F}(2,35)=7.34, p<0.01$. Students in the Kahoot-based IRS ( $\mathrm{M}=4.31, \mathrm{SD}=0.51)$ and Quizlet-based IRS $(\mathrm{M}=4.45, \mathrm{SD}=0.54)$ groups reported significantly higher self-efficacy of group learning than the control group $(\mathrm{M}=3.58, \mathrm{SD}=0.72)$.

\subsection{Focus Group Interview}

5.4.1. How Does This Learning Experience in the Remedial Classroom Differ from What You Used to Experience?

(1) Kahoot-based IRS group. Students in the Kahoot-based IRS group responded that Kahoot was a less stressful learning environment because of its lively and flexible platform; it was a more fun way of learning than the traditional remedial instruction. Generally, this learning experience improved not only the mathematics learning outcomes but the peer learning. Many students responded that they learned by playing Kahoot, and they found that their mathematics improved and that they were more confident toward mathematics learning. During the interviews, some students said they liked this kind of instruction and wished they could be in class more so that they could keep playing.

(2) Quizlet-based IRS group. Through the Quizlet-based IRS, students worked closely with their team members to try to solve the problem. This was not happening before. The students counted on each other, and the discussion was productive. The students believed Quizlet is a fun and interesting learning experience and definitely a good way to cultivate teamwork. Some students responded that during the activity, their answers to the questions would disappear due to the limitations of the internet connection. This led to a score deduction, and they had to answer the question again. Furthermore, if answering the questions wrong, the students needed to go back until they got it right. This made getting the right answers stressful.

(3) Traditional group. The students found collaborative group learning to be better than individual learning. Students seldom used to ask classmates or teachers questions in the class, but they could interact and enhance learning from each other with peer learning. The learning initiative was strong. While some students were usually late or did not want to go to class, after peer learning was introduced, they arrived on time and became more actively engaged.

5.4.2. Have You Observed Any Changes in You or Peer Learning as the Result of This Learning Experience? Can You Give an Example? How Did the Changes Happen and Why?

(1) Kahoot-based IRS group. The students responded they liked the simple platform of Kahoot that enabled group members to discuss possible solutions to the problems. To 
win the game, a group that normally did not work together became actively engaged in helping each other. The students liked using devices to collaboratively answer questions and to compete with other teams. This not only gave them a sense of group ownership but also increased friendships. Students were highly engaged and positive toward this kind of instruction.

(2) Quizlet-based IRS group. The students responded that most of their peers were enthusiastic about learning in the classroom. Within the groups, members worked collaboratively and tried their best to solve problems because they wanted to beat the other groups. Members did not normally pay much attention when in groups; however, with Quizlet Live, the students constantly helped each other find solutions together.

(3) Traditional group. The students found group collaborative learning to be better than individual learning. Students seldom used to asked classmates or teachers questions in the class, but with peer learning, they could teach and learn from each other. The learning initiative was strong. While some students were usually late or did not want to go to class, after peer learning was introduced, they arrived on time and became more actively engaged.

\section{Discussion}

This study aimed to investigate the effects of different IRSs on supporting students' mathematics performance, intrinsic motivation, and self-efficacy. The findings from quantitative and qualitative data sources are summarized below, and the implications for remedial instruction are also discussed.

\subsection{The Kahoot-Based IRS Remedial Classroom Had a Significantly Positive Effect Overall on Mathematics Learning Performance}

The Kahoot-based IRS group students significantly outperformed those in the other groups (Quizlet-based IRS and Control) in the mathematics post-test and the delayed tests. These findings on the superiority of Kahoot-based IRS are consistent with Fotaris et al. [40], who found a positive impact of the Kahoot gamification application on academic achievements. Göksün and Gürsoy [41] reported that the Kahoot application had a positive effect on the retention rate of students. The qualitative research results revealed that Kahootbased IRS allowed students to immediately implement knowledge, enhanced learning outcomes, and made students satisfied with the immediate feedback about their achievements, thereby increasing their self-esteem. As found in the interview data, students in the Quizlet-based IRS group indicated they had experienced internet speed problems, which may have led to not wanting to try again or to competition issues. Besides, it was determined that the Quizlet Live application's high Internet connection requirements and the questions and answers presented on different screens are distracting for learners.

Additionally, the delayed test of the Kahoot-based IRS group was significantly higher than the other groups. In the class, every group in the Kahoot-based IRS would thoroughly discuss each question as it appeared in sequence. This allowed deeper discussion, and the answers for the question were shown subsequently. Each group was highly motivated to gain scores. This process signifies the essence of game-based learning in that the competition and rewards of the gaming experience enhanced the level of engagement and interaction [42]. Thus, the students' improvement in motivation to learn the mathematics subjects reinforced the active learning. The Kahoot-based IRS acts as a stronger motivator for learners to immerse themselves in the lesson and to cultivate learners to learn from each other through cooperation. 
6.2. Students in the Kahoot-Based IRS Remedial Classroom Reported Higher Intrinsic Motivation in Interest and Choice, while the Quizlet-Based IRS Group Reported Higher Interest, Value, Effort, and Choice Than the Traditional Group. In Addition, Students in the Kahoot-Based IRS and Quizlet-Based IRS Groups Reported Significantly Higher Group Learning Self-Efficacy Than the Control Group

The Kahoot-based IRS seems to encourage deep learning and discussion [43]. More specifically, students in the Quizlet-based group reported more positive intrinsic motivation than the Kahoot-based IRS when compared to the control group. From the interview data, the students responded they had more concentration on the challenge, which resulted in less loss of time and more enjoyment in the activity. This experience was probably their first time using a mobile phone to learn during remedial instruction, and their expectations and excitement were high. The Quizlet-based groups seemed to stimulate a learning experience that would make the team members concentrate on their efforts. The game design is simple, and it pays attention to interaction and feedback. The rules are also extremely simple, and it emphasizes instant fun and makes students feel excited and happy. The team members enjoy the game. In the learning activities, if the students notice the design of the environment, they further enhance their learning motivation and produce better learning results.

In addition, the high perception of group-efficacy induced by the experience with either Kahoot-based or Quizlet-based IRS can be an important aspect in the success of the remedial instruction with an IRS [44,45].

\section{Conclusions}

This study aimed to investigate students' mathematics learning experience using different IRSs (Kahoot and Quizlet Live) technologies. We assessed students' opinions on whether IRSs technology could effectively promote their mathematics learning. The results showed that most learners found that IRSs tools effectively improved their conceptual understanding and knowledge construction, encouraged their participation in group and whole-class discussions, and improved their subject performance, learning interests, choice, and group self-efficacy. These findings raise some issues related to the affordability and limitations of IRSs technology which are addressed below.

The replications of the current study are needed. There are some limitations observed by the researchers, and suggestions are advised to overcome the problems. First, there was a time constraint. The intervention period seemed insufficient for most of the students, and this was evidenced by conversations between the researchers and some students after the class. Second, since the use of IRS is still a relatively new phenomenon, there is a potential novelty effect in current research. In the remedial classroom where we conducted this research, all students participating in the study used IRS for the first time. The novelty of using new technology made them work harder in the course, thereby affecting the IRS effect in this study. In light of this, future research should investigate the impact of IRS longitudinally to determine whether its effects will decrease as the IRS experience increases. Third, group dynamics are critical in peer interactions. For example, approaches, patterns, and perceptions, and motivation towards peer learning. Fourth, the number of participants in each group is relatively small due to the nature of remedial classrooms. Future studies should consider including larger groups of students.

Author Contributions: All authors contributed meaningfully to this study. Y.-M.H.-research topic; Y.-M.H. and C.-H.C.—data acquisition and analysis; W.-J.S.--methodology support; C.-H.C.—original draft preparation; C.-H.C.- -writing review and editing. All authors have read and agreed to the published version of the manuscript.

Funding: This research received no external funding.

Institutional Review Board Statement: Not applicable.

Informed Consent Statement: Not applicable.

Data Availability Statement: Not applicable. 
Conflicts of Interest: The authors declare no conflict of interest.

\section{Appendix A. Samples of Basic and Advanced Mathematics Learning Performance Tests}

1. It is known that $f(x)=3 x-4, g(x)=x+2$, and when $x=a$, the two function values are the same, then $(\mathrm{A})-1$ (B) 1 (C) -3 (D) 3

2. How many constant functions are in the following equation? (A) 1 (B) 2 (C) 3 (D) 4 $f(x)=3 x-5 g(x)=1 h(x)=0 m(x)=f(x)=|x|$

3. Two functions $y=f(x)=3 x-12$ and $y=g(x)=a x-6$ pattern intersect at point $(6, b)$, then $a+b=$ ? (A) 12 (B) 3 (C) 6 (D) 8

4. If the sum of the function values of a constant function at $x=3$ and $x=5$ is 10 , what is the function value of this constant value at $x=-5$ ? (A) 1 (B) 2 (C) 5 (D) 8

\section{References}

1. Gebru, M.T.; Phelps, A.J.; Wulfsberg, G. Effect of clickers versus online homework on students' long-term retention of general chemistry course material. Chem. Educ. Res. Pract. 2012, 13, 325-329. [CrossRef]

2. Miller, R.G.; Ashar, B.H.; Getz, K.J. Evaluation of an audience response system for the continuing education of health professionals. J. Contin. Educ. Health Prof. 2003, 23, 109-115. [CrossRef] [PubMed]

3. Yourstone, S.A.; Kraye, H.S.; Albaum, G. Classroom questioning with immediate electronic response: Do clickers improve learning? Decis. Sci. J. Innov. Educ. 2008, 6, 75-88. [CrossRef]

4. Butler, M.; Pyzdrowksi, L.; Walker, V.; Yoho, S. Studying personal response systems in a college algebra course. Investig. Math Learn. 2010, 2, 1-18. [CrossRef]

5. de Grez, L.; Valcke, M. Student response system and how to make engineering students learn oral presentation. Int. J. Eng. Educ. 2013, 29, 940-947.

6. Bullock, D.W.; LaBella, V.P.; Clingan, T.; Ding, Z.; Stewart, G.; Thibado, P.M. Enhancing the student-instructor interaction frequency. Phys. Teach. 2002, 40, 535-541. [CrossRef]

7. Shaffer, D.M.; Collura, M.J. Evaluating the effectiveness of a personal response system in the classroom. Teach. Psychol. 2009, 36, 273-277. [CrossRef]

8. Duncan, D. Clickers in the Classroom; Pearson, Addison Wesley: Boston, MA, USA, 2005.

9. Chien, Y.T.; Chang, Y.H.; Chang, C.Y. Do we click in the right way? A meta-analytic review of clicker-integrated instruction. Educ. Res. Rev. 2016, 17, 1-18. [CrossRef]

10. Gagné, R.M.; Briggs, L.J.; Wager, W.W. Principles of Instructional Design, 4th ed.; Harcourt Brace Jovanovich College Publishers: Forth Worth, TX, USA, 1992.

11. Reigeluth, C. Instructional-Design Theories and Models: A New Paradigm of Instructional Theory; Lawrence Erlbaum: Mahwah, NJ USA, 1999; Volume II.

12. Dick, W.; Carey, L.; Carey, J.O. The Systematic Design of Instruction; Longman: New York, NY, USA, 2004.

13. Hardré, P.L.; Ge, X.; Thomas, M.K. Toward a model of development for instructional design expertise. Educ. Technol. 2005, 45, 53-57.

14. Fosnot, C.T. Constructivism: Theory Perspective and Practice; Teachers College Press: New York, NY, USA, 1996.

15. National Research Council. What Is the Influence of the National Science Education Standards? National Academy Press: Washington, DC, USA, 2003.

16. Wilkins, J.L.M.; Ma, X. Modeling change in student attitude toward and beliefs about mathematics. J. Educ. Res. 2003, 97, 52-63. [CrossRef]

17. Kargar, M.; Tarmizi, R.A.; Bayat, S. Relationship between mathematical thinking, mathematics anxiety and mathematics attitudes among university students. Procedia Soc. Behav. Sci. 2010, 8, 537-542. [CrossRef]

18. Maloney, E.A.; Schaeffer, M.W.; Beilock, S.L. Mathematics anxiety and stereotype threat: Shared mechanisms, negative consequences and promising interventions. Res. Math. Educ. 2013, 15, 115-128. [CrossRef]

19. Lazakidou, G.; Retalis, S. Using computer supported collaborative learning strategies for helping students acquire self-regulated problem-solving skills in mathematics. Comput. Educ. 2010, 54, 3-13. [CrossRef]

20. Kebritchi, M.; Hirumi, A.; Bai, H. The effects of modern mathematics computer games on mathematics achievement and class motivation. Comput. Educ. 2010, 55, 427-443. [CrossRef]

21. Plass, J.L.; O’Keefe, P.A.; Homer, B.D.; Case, J.; Hayward, E.O.; Stein, M.K.; Perlin, K. The impact of individual, competitive, and collaborative mathematics game play on learning performance and motivation. J. Educ. Psychol. 2013, 105, 1050-1066. [CrossRef]

22. Shin, N.; Sutherland, L.M.; Norris, C.A.; Soloway, E. Effects of game technology on elementary student learning in mathematics. Br. J. Educ. Technol. 2012, 43, 540-560. [CrossRef]

23. Caldwell, J.E. Clickers in the large classroom: Current research and best-practice tips. CBE-Life Sci. Educ. 2007, 6, 9-20. [CrossRef]

24. Wang, A.I. The wear out effect of a game-based student response system. Comput. Educ. 2015, 82, 217-227. [CrossRef]

25. Hunsu, N.J.; Adesope, O.; Bayly, D.J. A meta-analysis of the effects of audience response systems (clicker-based technologies) on cognition and affect. Comput. Educ. 2016, 94, 102-119. [CrossRef] 
26. Levin, H.M.; Calcagno, J.C. Remediation in the community college: An evaluator's perspective. Community Coll. Rev. 2008, 35, 181-207. [CrossRef]

27. Barnett, S.M.; Ceci, S.J. When and where do we apply what we learn? A taxonomy for far transfer. Psychol. Bull. 2002, 128, 612-637. [CrossRef]

28. Webb, N.M. Task-related verbal interaction and mathematics learning in small groups. J. Res. Math. Educ. 1991, 22, 366-389. [CrossRef]

29. Vygotsky, L.S. Mind in Society; Harvard University Press: Cambridge, UK, 1978.

30. Resnick, L.B. Constructing knowledge in School. Development and Learning: Conflict or Congruence; Liben, L.S., Ed.; Erlbaum: Hillsdale, NJ, USA, 1987.

31. King, A. Verbal interaction and problem-solving within computer-assisted cooperative learning groups. J. Educ. Comput. Res. 1989, 5, 1-15. [CrossRef]

32. King, A.; Rosenshine, B. Effects of guided cooperative questioning on children's knowledge construction. J. Exp. Educ. 1993, 61, 127-148. [CrossRef]

33. Lantz, M.E.; Stawiski, A. Effectiveness of clickers: Effect of feedback and the timing of questions on learning. Comput. Hum. Behav. 2014, 31, 280-286. [CrossRef]

34. Kvadsheim, R.; Haugerud, H.; Hammer, H.L.; Bratterud, A.; Habib, L. Does clicker use improve exam scores? A controlled randomized experiment in a bachelor-level course in software engineering. Int. J. Eng. Educ. 2015, 31, 505-520.

35. Sun, C.Y. Influence of polling technologies on student engagement: An analysis of student motivation, academic performance, and brainwave data. Comput. Educ. 2014, 72, 80-89. [CrossRef]

36. Quizlet. About Quizlet. 2019. Available online: https:/ quizlet.com/zh-tw/mission (accessed on 6 April 2021).

37. Deci, E.L.; Ryan, R.M. The "what" and "why" of goal pursuits: Human needs and the self-determination of behavior. Psychol. Inq. 2000, 11, 227-268. [CrossRef]

38. Wang, S.L.; Lin, S.S. The effects of group composition of self-efficacy and collective efficacy on computer-supported collaborative learning. Comput. Hum. Behav. 2007, 23, 2256-2268. [CrossRef]

39. Pintrich, P.; Smith, D.A.; Garcia, T.; McKeachie, W.J. A Manual for the Use of the Motivated Strategies for Learning Questionnaire (MSLQ); National Center for Research to Improve Postsecondary Teaching and Learning: Ann Arbor, MI, USA, 1991.

40. Fotaris, P.; Mastoras, T.; Leinfellner, R.; Rosunally, Y. Climbing up the leaderboard: An empirical study of applying gamification techniques to a computer programming class. Electron. J. e-Learn. 2016, 14, 94-110.

41. Göksün, D.O.; Gürsoy, G. Comparing success and engagement in gamified learning experiences via Kahoot and Quizizz. Comput. Educ. 2019, 135, 15-29. [CrossRef]

42. Chen, C.H. The impacts of peer competition-based science gameplay on conceptual knowledge, intrinsic motivation, and learning behavioral patterns. Educ. Technol. Res. Dev. 2019, 67, 179-198. [CrossRef]

43. Shih, J.L.; Shih, B.J.; Shih, C.C.; Su, H.Y.; Chuang, C.W. The influence of collaboration styles to children's cognitive performance in digital problem-solving game "William Adventure": A comparative case study. Comput. Educ. 2010, 55, 982-993. [CrossRef]

44. Hoffman, B.; Spatariu, A. The influence of self-efficacy and metacognitive prompting on math problem-solving efficiency. Contemp. Educ. Psychol. 2008, 3, 875-893. [CrossRef]

45. Sins, P.H.M.; Van Joolingen, W.R.; Savelsbergh, E.R.; van Hout-Wolters, B. Motivation and performance within a collaborative computer-based modeling task: Relations between students' achievement goal orientation, self-efficacy, cognitive processing, and achievement. Contemp. Educ. Psychol. 2008, 33, 58-77. [CrossRef] 